\title{
Impact of Meteorological Parameters on Dispersion Modeling of Sulfur Dioxide from Gas Flares (Case Study: Sirri Island)
}

\author{
M. A. Mirrezaei* \\ Department of Environmental Engineering, College of Engineering, University of Tehran, Tehran, Iran
}

\section{$P A P E R \quad I N F O$}

\section{Paper history:}

Received 30 August 2019

Accepted in revised form 24 November 2019

\section{Keywords:}

California Puff Model

Flares

Meteorological Data

Oil Field

Simulation

Weather Research and Forecasting

\begin{abstract}
$A \quad B \quad S T R A C T$
In this study, in 2011 for the duration of two months, the dispersion of a major air pollutant, sulfur dioxide from gas flares of an oil field, in Iran, was investigated. Due to the complexity of meteorological parameters in modeling area, California Puff (CALPUFF) model was used in this study. CALPUFF is a more advanced model than AERMOD which considers the effects of meteorological parameters in coastal areas, which was applied with meteorological and geophysical parameters produced by the Weather Research and Forecasting (WRF) model for the selected days of modeling period to investigate the impact of these parameters on modeling results. Since there is no option in the model for flares, flare parameters including emission rate and effective height and diameter were calculated based on EPA method to simulate better the real condition of flaring. Simulation results revealed that CALPUFF model could adequately express the effect of meteorological condition on results of modeling in each hour of the simulation period. The results of the simulation showed that low-height flares have the most impact on the ground level concentration of air pollutant on the island. The effects of elevated flares were at a far distance from flaring activity and mostly occurred outside of the island. CALPUFF model showed excellent compatibility with meteorological data produced by WRF and could properly account for the effect of meteorological and terrain parameters on dispersion modeling.
\end{abstract}

doi: $10.5829 /$ ijee.2019.10.04.10

\section{INTRODUCTION}

Flaring is a conventional and reliable means for disposal of waste gas from oil and gas facilities. This process is an indispensable part of oil and gas production, which require safe disposal of flammable waste gases [1]. Despite the broad application of flaring, this process unleashes a huge amount of air pollutants to the environment. The diversity and types of released pollutants are governed by the composition of inlet gas to the flares and the combustion efficiency, which depends on several factors including temperature, wind speed, the velocity of gas exiting flare and so forth [2]. Major air pollutants released from gas flares are sulfur dioxide, nitrogen oxide, carbon monoxide, non-methane volatile organic compounds, particulate matter, methane, and carbon monoxide [3]. $\mathrm{SO}_{2}$ can be emitted from flares if the sulfur component exists in the flared waste gas. $\mathrm{NO}_{\mathrm{X}}$ production is strongly dependent on temperature and formed by the fixation of the molecular nitrogen from the air. Emission of $\mathrm{CO}$ from the flare is due to incomplete combustion. Iran is a significant exporter of oil, and its economy, growth and Policy are highly dependent on oil production. Gas flaring is a considerable amount and results in various environmental impacts including climate change, acid rain, agricultural destruction, and especially adversely affected on human health. Detailed study of the dispersion of the air pollutants from gas flares is a vital process to specify the air quality of oil field and regions close to them and find solutions to moderate their attendant impacts. The application of air dispersion models has been increased rapidly in recent years, and these models with applying monitoring activities become an effective method in air quality evaluation. The main features of air dispersion models are their low-cost application and acceptable results which incorporate the impacts of meteorology, topography, source type in a particular broad area [4]. Dispersion models are in general based on Gaussian approximation of horizontal and vertical profiles of concentration. They contain algorithms to include the effect of sources, topology, wind speed and direction and chemical reactions [5]. One of the most commonly used models by regulatory agencies in this area is CALPUFF. The performance of the CALPUFF modeling system has been evaluated in several studies $[6,7$, $8,9,10]$. Modeling the dispersion of air pollutants emitted from gas flares in locations like those that Islands require considering additional factors such as complex meteorological and terrain parameters. Incorporating all these 
factors with the lack of meteorological data in locations such as islands requires a thorough study that is a necessity for locations like Iran, which account for a significant amount of flaring in the world and have several flaring sites on islands. Coupling dispersion models with prognostic meteorological models is an efficient way for locations with a lake of meteorological data. This method was used in some recent studies:

Kesarkar et al. [11] mentioned that AERMOD requires hourly surface and upper air meteorological observations for simulating the pollutant dispersion. The required meteorological parameters are derived from high-resolution prognostic simulations using WRF model to overcome this difficulty. The methodology for coupling of air quality model (AERMOD) with regional weather prediction model (WRF) was discussed. The methodology of coupling a prognostic regional weather model with an air pollution model for simulating pollutant dispersion has shown encouraging results, and the system has potential to overcome the limitation of unavailability of required local meteorological observations. Abdul-Wahab et al. [12] investigated the transport and dispersion patterns of $\mathrm{SO}_{2}$ originating from Mina Al-Fahal refinery, in the Sultanate Oman by employing California Puff (CALPUFF) dispersion modeling system. The CALPUFF modeling system was coupled with WRF to obtain the meteorological fields of the study area. The results of the study indicated that the performance of the CALPUFF was better than that of ISCST. Abdul-Wahab et al. [12] applied CALLPUFF and MM5 model to study the dispersion pattern of $\mathrm{SO}_{2}$ emission from a refinery in Oman. The results of study well matched with observation data with minor differences in magnitudes. Also, a comparison between modeling data and the regulatory limits was carried out. The results determined that the concentration of $\mathrm{SO}_{2}$ was lower than regulatory limits in communities nearby refinery.

Ghannam and El-Fadel [13] investigated the role of different sources to ground-level concentrations of carbon monoxide $(\mathrm{CO})$, nitrogen dioxide $\left(\mathrm{NO}_{2}\right)$, and $\mathrm{PM}_{10}$ in a coastal urban area by considering emissions from an industrial complex with multiple stacks, quarrying activities, and a nearby highway. In this study, a coupled CALPUFF/MM5 model was used. In another recent study, dispersion modeling of $\mathrm{PM}_{10}, \mathrm{SO}_{2}$ and $\mathrm{NOx}$ were conducted by application of combined WRF/CALPUFF model for Benxi city in China [14]. The result of this study has shown that the predicted concentrations by the CALPUFF model were in good agreement with monitoring sites data. By reviewing the works were done on this topic, it is evident that few works were carried out for modeling of gas flares. Furthermore, modeling of gas flares is different from other point sources like regular stacks and requires calculation of flare parameters before applying dispersion models. Also, lack of meteorological data in remote areas like islands could be significant uncertainty in modeling activity. Coupling metrological models with dispersion models were tested in some recent works and the results in most cases showed good agreement between modeling results and observational data from monitoring stations. Consequently, application of air pollution dispersion models with metrological models like WRF, which is the next generation of mesoscale numerical weather prediction systems, could be a useful tool in the prediction of pollutants concentrations in areas around gas flares.

In this work, modeling the dispersion of $\mathrm{SO}_{2}$ from gas flares on an island will be done with CALPUFF model by embedding calculated parameters for gas flares in the model. This modeling will be performed by application of CALPUFF-WRF coupled model for certain days to investigate the effect of coastal area and related meteorological parameters on modeling results.

\section{MATERIALS AND METHODS}

\section{Study area}

Sirri Island has been selected for this study. This island is in the Persian Gulf, which belongs to Iran and situated at about $75 \mathrm{~km}$ off the coast of Iran. The island located in $76 \mathrm{~km}$ of Bandar Lengeh and administered by Hormozgan Province. It covers an area of 17.3 kilometers squared. Sirri Island has hot and humid weather. The average temperature of the island ranges from about 40 degrees centigrade in July to about 12.5 degrees centigrade in the coldest month of the year [15]. The highest point on this island is about 24 meters above the sea level, and most of the island is flat. The oil production of the island is more than 100,000 barrels per day [16]. There are multiple oil and gas exploration and production facilities on this island. These oil and gas facilities produce a considerable amount of air pollutants. Flares are one of the significant sources of air pollution in this region. Figure 1 shows the location of major flares on the island.

\section{Dispersion modeling}

CALPUFF is an advanced dispersion model, which applies Lagrangian puff Gaussian algorithm to predict concentrations of air pollutants downwind of emission sources. In this regard, CALPUFF requires 3D meteorological fields [17]. It could be possible by application of surface observation and upper air meteorological data or prognostic meteorological models, like MM5 and WRF. The first choice is not available in many parts of Iran because of inconsistent meteorological data from weather stations. The second approach also has limitations due to high computational requirements. These limitations could be resolved by the support of related organization and agencies. In this study, WRF model will be used to produce meteorological input data for CALPUFF modeling system. MMIF is an interface software that recently released to construct the required input meteorological parameters for CALPUFF model [18]. This software is used in this investigation, to prepare the 3D meteorological input of CALPUFF with WRF output data.

\section{Meteorological modeling}

The Weather Research and Forecasting (WRF) model is a system that used for numerical weather forecasting and atmospheric conditions studies in both operational and research applications. The WRF model contains various physics and dynamic schemes that provide several choices for applying different combination of physics and dynamics to the desired area. Finding optimum configuration for WRF model requires several runs of the model for different physics and dynamic that needs high computational time and power. Azadi et al. [19] applied six different configurations of 


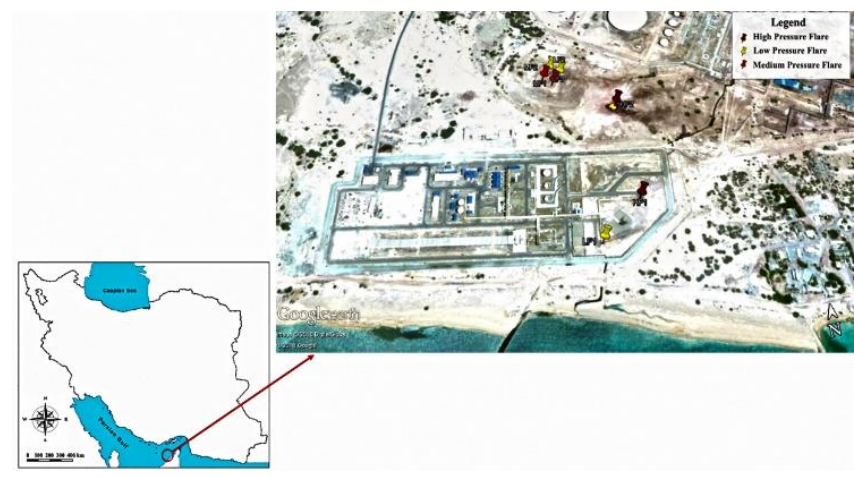

Figure 1. Location of major flares in Sirri island

physics and dynamics to find the most appropriate combination for forecasting of daily precipitation over Iran. In this study, the physics and dynamic configuration [19]) will be used to run WRF model on Sirri Island. Three domains were considered for WRF configuration with 12, 4 and 1.33kilometer resolutions for horizontal grid respectively and 27 levels in the vertical direction (Figure 2). The center coordinates of domains are $25.914259^{\circ} \mathrm{N}$ and $54.527322^{\circ} \mathrm{E}$ that is located on Sirri Island.

The WRF model was run for two five days' period from 29 January 2011 to 2 February 2011 and 20 October to 24 October 2011. The output of WRF was compared with observational data from Sirri Island weather station to evaluate the result of the model with observed meteorological data. The following statistical functions were used for assessing the performance of WRF model:

Mean Average Error $(M A E)$ :

$$
M A E=\sum_{i=1}^{n} \frac{\left|M_{i}-O_{i}\right|}{n}
$$

where $\mathrm{M}_{\mathrm{i}}$ is the modeled value for cell $\mathrm{i}, \mathrm{O}_{\mathrm{i}}$ is the observed value for cell $\mathrm{i}$, and $\mathrm{n}$ is the number of values analyzed.

Root Mean Square Error (RMSE):

$$
R M S E=\sqrt{\sum_{i=1}^{n} \frac{\left(M_{i}-O_{i}\right)^{2}}{n}}
$$

Root Mean Square Error (RMSE) is similar to $M A E$ but more sensitive to occasional significant errors due to its quadratic term.

Bias $(B I A S)$ :

$$
B I A S=\sum_{i=1}^{n} \frac{\left(M_{i}-O_{i}\right)}{n}
$$

Bias provides information on the trend of the model to overestimate or underestimate a variable.

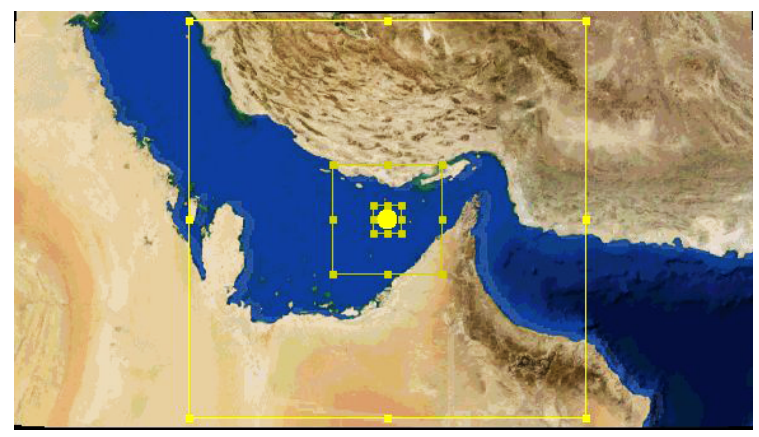

Figure 2. Three domain selected for running WRF
The coefficient of Determination $\left(R^{2}\right)$ :

The coefficient of determination detrmines how well data points fit a statistical model. The general definition of the coefficient of determination is:

$$
R^{2}=1-\frac{S S_{\text {res }}}{S S_{\text {total }}}
$$

where $\mathrm{SS}_{\text {res }}$ is the sum of squares of residuals and for when observed value is shown by $y_{i}$ and modeled value with $f_{i}$, it could be represented by:

$$
\text { SSres }=\sum_{i}\left(y_{i}-f_{i}\right)^{2}
$$

$\mathrm{SS}_{\text {total }}$ is the total sum of squares and when the mean of the observed data represent by $\bar{y}$, it can be expressed by Equation (7).

$$
\begin{aligned}
& S S_{\text {total }}=\sum_{i}\left(y_{i}-\bar{y}\right)^{2} \\
& \bar{y}=\frac{1}{n} \sum_{i=1}^{n}\left(y_{i}\right)
\end{aligned}
$$

\section{Source parameters}

Flares are considered as point sources; however, a flare option is not available in CALPUFF model. Therefore, calculation of plume rise and effective stack diameter based on the heat release from flare require being done. This difference is due to a flare releases heat at the stack top and also heat loss by radiation [20].

Effective release height and effective diameter can be calculated based on EPA guideline from Equation (8) through Equation (10) [21]:

$$
\begin{aligned}
& H_{\text {effective }}=H_{\text {actual }}+0.00456\left(\frac{H}{4.1868}\right)^{0.478} \\
& d=9.88 \times 10^{-4} \times Q_{H}^{0.5} \\
& Q_{H}=(1-F) H
\end{aligned}
$$

where, $\mathrm{H}_{\text {effective }}$ is effective stack height $(\mathrm{m}), \mathrm{H}_{\text {actual }}$ is actual stack height $(\mathrm{m}), \mathrm{H}_{\mathrm{r}}$ is net heat release rate $(\mathrm{J} / \mathrm{s}), \mathrm{H}$ is total heat release rate $(\mathrm{Cal} / \mathrm{s}), \mathrm{Q}_{\mathrm{H}}$ is source heat release $(\mathrm{Cal} / \mathrm{s}), \mathrm{F}$ is radiative loss factor $(\%), \mathrm{d}$ is diameter $(\mathrm{m})$. The assumption in Equation (10) is that $55 \%$ of total heat released from the flare is lost by radiation that is the maximum heat loss suggested by Leahey and Davies [22].

Calculation of the emission of $\mathrm{SO}_{2}$ is based on the sulfur content of input gas to the flare and combustion efficiency. The emission is calculated by Equation (11):

$$
\mathrm{SO}_{2}\left(\frac{\mathrm{g}}{\mathrm{S}}\right)=\text { combustion efficiency } \times \frac{\mathrm{MW} \mathrm{SO}_{2}}{\mathrm{MW} \mathrm{Sulphur} \mathrm{Content}}
$$

The calculated parameters for flares in the study area is represented in Table 1.

\section{CALPUFF Model}

As mentioned before, CALPUFF requires three-dimensional meteorological and geophysical parameters that are created by CALMET preprocessor. MMIF program was used as an alternative for CALMET program to construct these parameters for CALPUFF model. CALPUFF which is the central processor of CALPUFF modeling system calculates the concentration of pollutant based on the puff Gaussian algorithms and 3D meteorological and geophysical parameters. The CALPro, the GUI for CALPUFF model, was used in this study to calculate the concentration of pollutants with meteorological and geophysical parameters produced by 
TABLE 1. Calculated emission rate, effective height and diameter for flares in Sirri Island

\begin{tabular}{lccc}
\hline Flare Type & $\begin{array}{c}\text { Emission Rate } \\
\mathbf{S O}_{\mathbf{2}}(\mathbf{g} / \mathbf{s})\end{array}$ & $\begin{array}{c}\text { Effective } \\
\text { Height }(\mathbf{m})\end{array}$ & $\begin{array}{c}\text { Effective } \\
\text { diameter }(\mathbf{m})\end{array}$ \\
\hline Low Pressure & 125.939 & 10.6 & 3.1 \\
Low Pressure & 125.939 & 10.6 & 3.1 \\
Low Pressure & 125.939 & 10.6 & 3.1 \\
Low Pressure & 42.461 & 21.1 & 3.1 \\
Medium Pressure & 0.183 & 12.5 & 3.3 \\
Medium Pressure & 0.183 & 12.5 & 3.3 \\
High Pressure & 2.698 & 87.8 & 4.5 \\
High Pressure & 412.198 & 107.7 & 5.4 \\
\hline
\end{tabular}

MMIF program. Since there is no option in CALPUFF model for modeling flare sources, the modified parameters of height and diameter of the stack with a calculated emission rate of pollutant were used as source input parameters for CALPUFF model. CALPUFF model was run for two five days period from 29 January 2011 to 2 February 2011 and 20 October 2011 to 24 October 2011. Short-term time averages of 1, 24hour and total period was investigated to study the effect of hourly meteorological parameters on results of modeling. Also, modeling was carried out separately for both short and elevated flares to consider the contribution of these flares on ground level concentration. CALPUFF results were used by CALPOST to produce the average concentration of pollutants for desired time average. Figure 3 shows the data flow in CALPUFF modeling in this study.

\section{RESULTS AND DISCUSSION \\ WRF outputs}

WRF model was run for two five days' period starting from 29 January 2011 to 2 February 2011 and 20 October 2011 to 24 October 2011. The comparison of WRF output results with observed values that were taken from Sirri's weather station is shown for wind direction, wind speed, temperature and pressure in Figure 4.

WRF outputs show good agreement with observed wind direction, wind speed, temperature and pressure. The observed values of these parameters were recorded for every 3 hours, starting from 3 am to $15 \mathrm{pm}$ in each day in Sirri's weather station. Average of statistical functions including Mean Average Error (MAE), Root Mean Square Error (RMSE), and bias with coefficient of determination $\left(\mathrm{R}^{2}\right)$ were

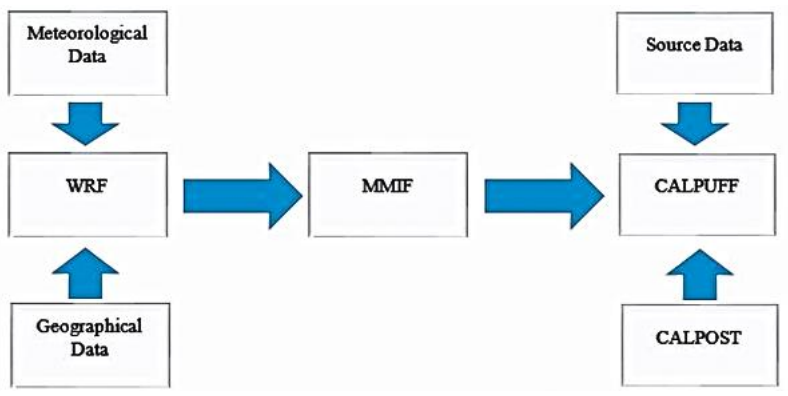

Figure 3. Data flow in CALPUFF modeling system

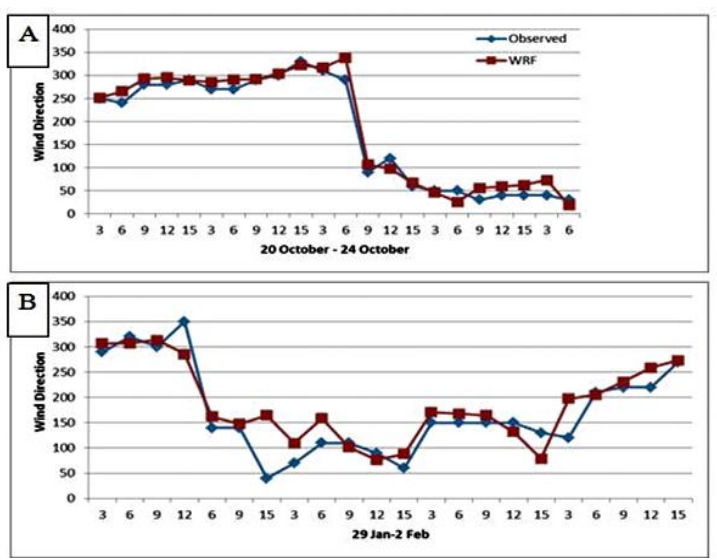

(1)
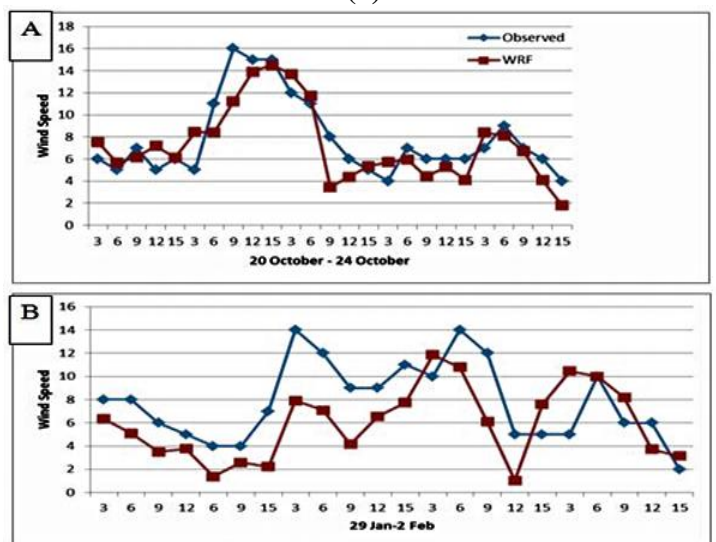

(2)
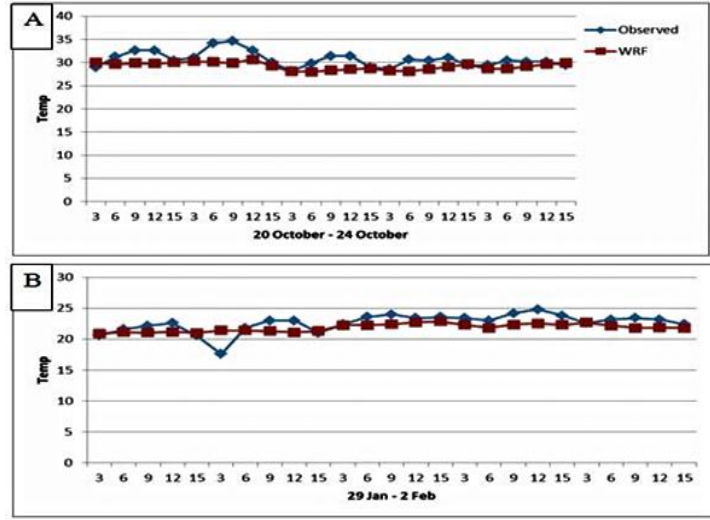

(3)

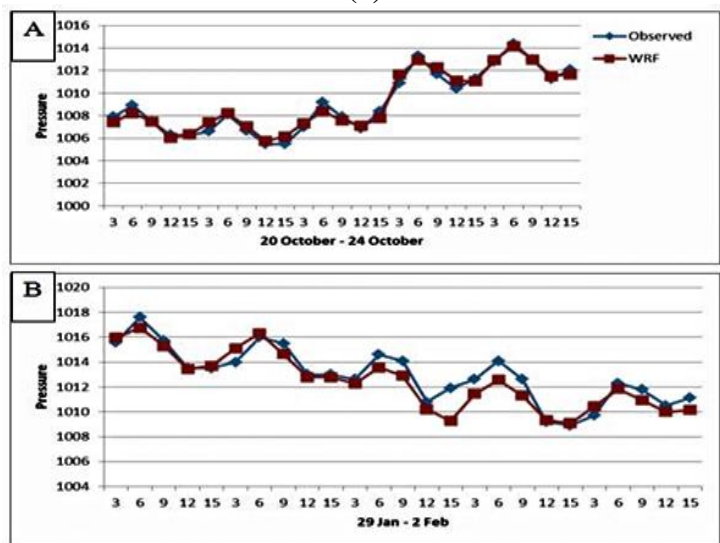

(4)

Figure 4. Comparison of Observed and WRF computed values of wind direction (1), wind speed (2), temperature (3) and pressure (4); for A) 20 October 2011 to 24 October 2011 B) 29 January 2011 to 2 February 2011 
calculated and represented in Table 2 for wind direction, wind speed, temperature, and pressure of each period for better representation the comparison of the output results from WRF model and observed meteorological parameters.

Table 2 proves that WRF model had an acceptable prediction of meteorological parameters. Prediction of wind direction is similar to observed values and especially in the period from 29 January to 2 February, the predicted, and observed values have a high dependency, and the amount of error is acceptable. Wind speed, temperature, and pressure also have the same pattern, and as the value of Bias shows, the model underestimates these parameters except for pressure in the period from 20 October to 24 October with the amount of lower than $2 \mathrm{~m} / \mathrm{s}$ for wind speed, $1.5^{\circ} \mathrm{C}$ for temperature and $0.5 \mathrm{mbar}$ for pressure. Except for temperature in 20 October to 24 October, all other parameters have high coefficient of determination, which shows the good replication of observed values with model predictions. Although temperature has low, value of $\mathrm{R}^{2}$ but its error is lower than $1.5^{\circ} \mathrm{C}$, which could be considered acceptable. The overall performance of WRF model in prediction of meteorological parameters for application in CALPUFF dispersion model was satisfactory and could be a great asset to investigating the dispersion of air pollutants in each hour with different meteorological conditions that occur during a day.

\section{CALPUFF outputs}

The CALPUFF model was run in this study by using WRF output data as input meteorological and geophysical parameters for two five-day periods starting from 29 January 2011 to 2 February 2011 and 20 October 2011 to 24 October 2011to investigate the effect of hourly meteorological parameters on the dispersion of sulfur dioxide emitted from flares. The modeling was carried out for 1hour; 24 hour and full period averages and the result of simulation for highest predicted values of each averaging period with the highest total period are represented in Table 3 .

TABLE 2. Average of statistical functions for wind direction and speed, temperature and pressure

\begin{tabular}{|c|c|c|c|c|}
\hline Parameter & MAE & RMSE & BIAS & $\mathbf{R}^{2}$ \\
\hline $\begin{array}{l}\text { Wind direction } \\
29 \text { Jan }-2 \text { Feb }\end{array}$ & 26.03 & 41.19 & - & 0.79 \\
\hline $\begin{array}{l}\text { Wind direction } \\
20 \mathrm{Oct}-24 \mathrm{Oct}\end{array}$ & 15.04 & 18.69 & - & 0.98 \\
\hline $\begin{array}{l}\text { Wind speed } \\
29 \text { Jan }-2 \text { Feb }\end{array}$ & 1.61 & 1.99 & -0.50 & 0.38 \\
\hline $\begin{array}{l}\text { Wind speed } \\
20 \mathrm{Oct}-24 \mathrm{Oct}\end{array}$ & 2.68 & 3.46 & -1.63 & 0.70 \\
\hline $\begin{array}{l}\text { Temperature } \\
\text { 29 Jan -2 Feb }\end{array}$ & 1.65 & 2.08 & -1.51 & 0.38 \\
\hline $\begin{array}{l}\text { Temperature } \\
20 \text { Oct }-24 \text { Oct }\end{array}$ & 1.15 & 1.40 & -0.75 & 0.23 \\
\hline $\begin{array}{l}\text { Pressure } \\
\text { 29 Jan -2 Feb }\end{array}$ & 0.72 & 0.92 & -0.48 & 0.97 \\
\hline $\begin{array}{l}\text { Pressure } \\
20 \text { Oct }-24 \text { Oct }\end{array}$ & 0.38 & 0.45 & 0.03 & 0.87 \\
\hline
\end{tabular}

TABLE 3. First rank of highest 1,24 and total period average concentration of $\mathrm{SO}_{2}$

\begin{tabular}{cccc}
\hline Pollutant & $\begin{array}{c}\text { Period } \\
(\text { year/month/day, start time) }\end{array}$ & $\begin{array}{c}\text { Average } \\
\text { period (hour) }\end{array}$ & $\begin{array}{c}\text { Peak value } \\
\left(\boldsymbol{\mu g} / \mathbf{m}^{3}\right)\end{array}$ \\
\hline \multirow{6}{*}{$2011 / 1 / 3018: 00$} & 1 & 1394.01 \\
$\mathrm{SO}_{2}$ & $2011 / 10 / 2208: 00$ & & 1014.28 \\
& $2011 / 1 / 2923: 00$ & 24 & 137.63 \\
& $2011 / 10 / 2023: 00$ & & 525.69 \\
& $2011 / 1 / 2900: 00$ & Period & 59.96 \\
& $2011 / 10 / 2000: 00$ & & 28.59 \\
\hline
\end{tabular}

Figure 5 represents the wind vectors with the terrain of modeling domain for the highest value of 1 hour average period of $\mathrm{SO}_{2}$ on 29 January to 2 February period. As it is shown, the wind speed is lower than $5 \mathrm{~m} / \mathrm{s}$ and in the range of 0.01 to $5.01 \mathrm{~m} / \mathrm{s}$ which by a clear sky of this region conditionally stable condition was existed. Figure 6 Shows the stability of atmosphere in this condition with the distribution of $\mathrm{SO}_{2}$ around flares.

In these hours, the mixing height was as low as $140 \mathrm{~m}$, and by considering elevated flares release height on the island, the

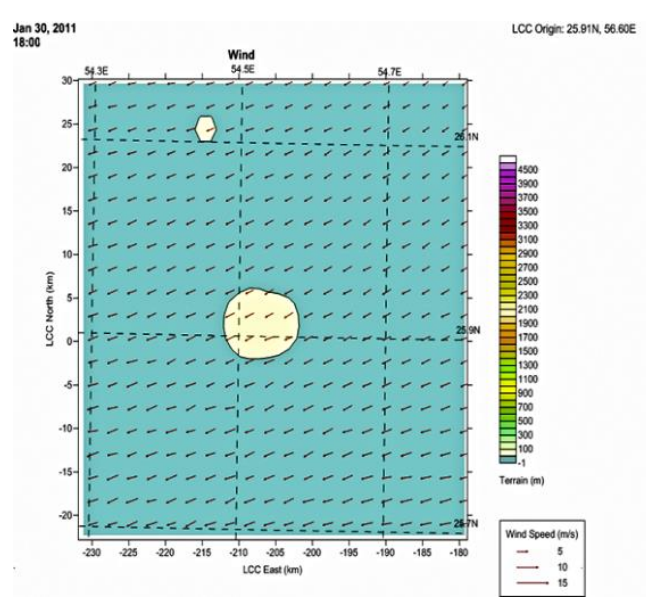

Figure 5. Wind vectors and terrain of modeling domain at 30 January 2011, 18:00

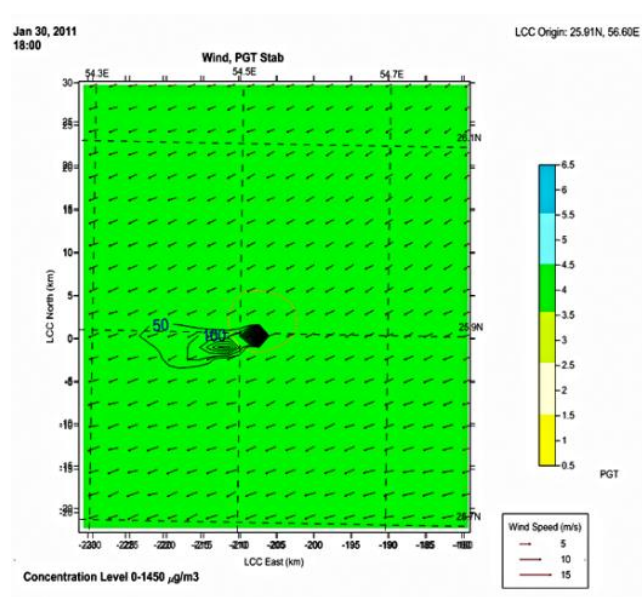

Figure 6. Contours of $\mathrm{SO}_{2}$ concentration with stability 30 January 2011, 18:00 
dispersion of $\mathrm{SO}_{2}$ must occur above the mixing height. This situation caused high ground level concentration around flares that caused by flares with a lower elevation. To illustrate this condition better, CALPUFF model was run for two cases, first only for flares with short heights and the second one, for flares with high elevation. Figure 7 represent these two cases.

The emission from elevated flares is distributed in different directions in comparison with two low-height flares. It can be understood that by considering the direction of the wind in higher elevations as shown in Figure 8, the maximum

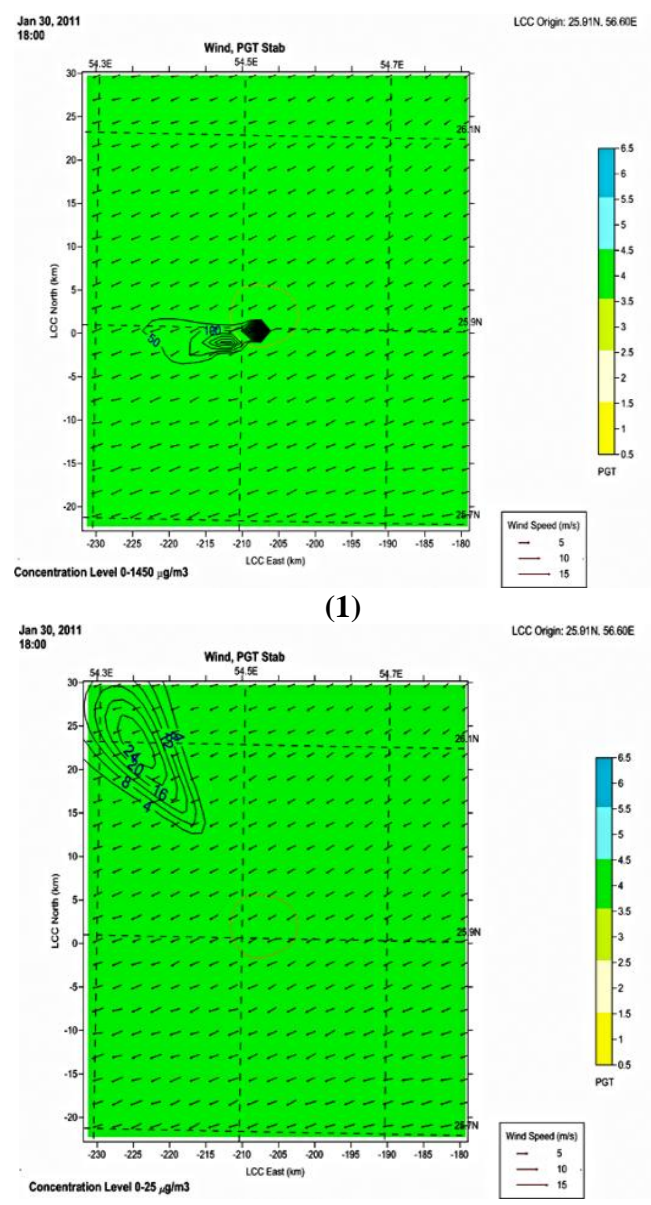

(2)

Figure 7. Contours of $\mathrm{SO}_{2}$ concentration distribution for considering only (1) short flares and (2) elevated flares, 30 January 2011, 18:00

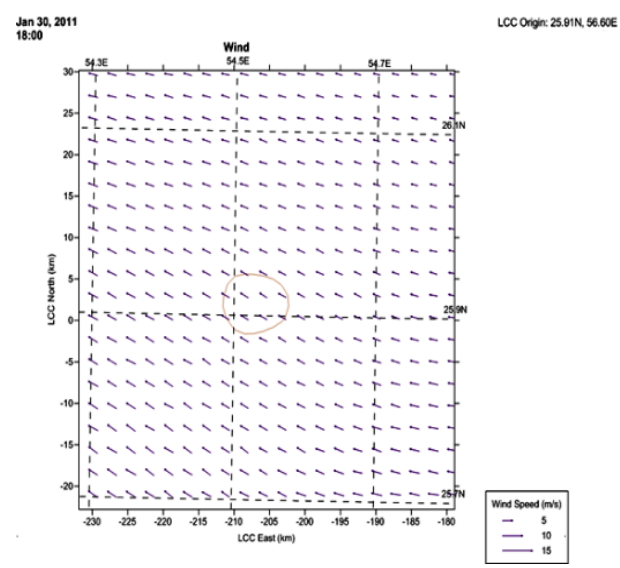

Figure 8. Vectors of wind at 160-meter height concentration was mostly caused by low-height flares and distribution of pollutant concentration is not far from sources. Also, maximum concentration occurred in about 400 meters from low-height flares since the stable condition reduces horizontal and vertical dispersion of $\mathrm{SO}_{2}$. This condition also existed near sunrise in October. As it is represented in Figure 9, low-height flares had the most impact on maximum concentration around flaring activity. In this condition like maximum concentration in January period, when the pollutant released from low-height flares, it cannot disperse well in both horizontal and vertical directions. It caused by stability
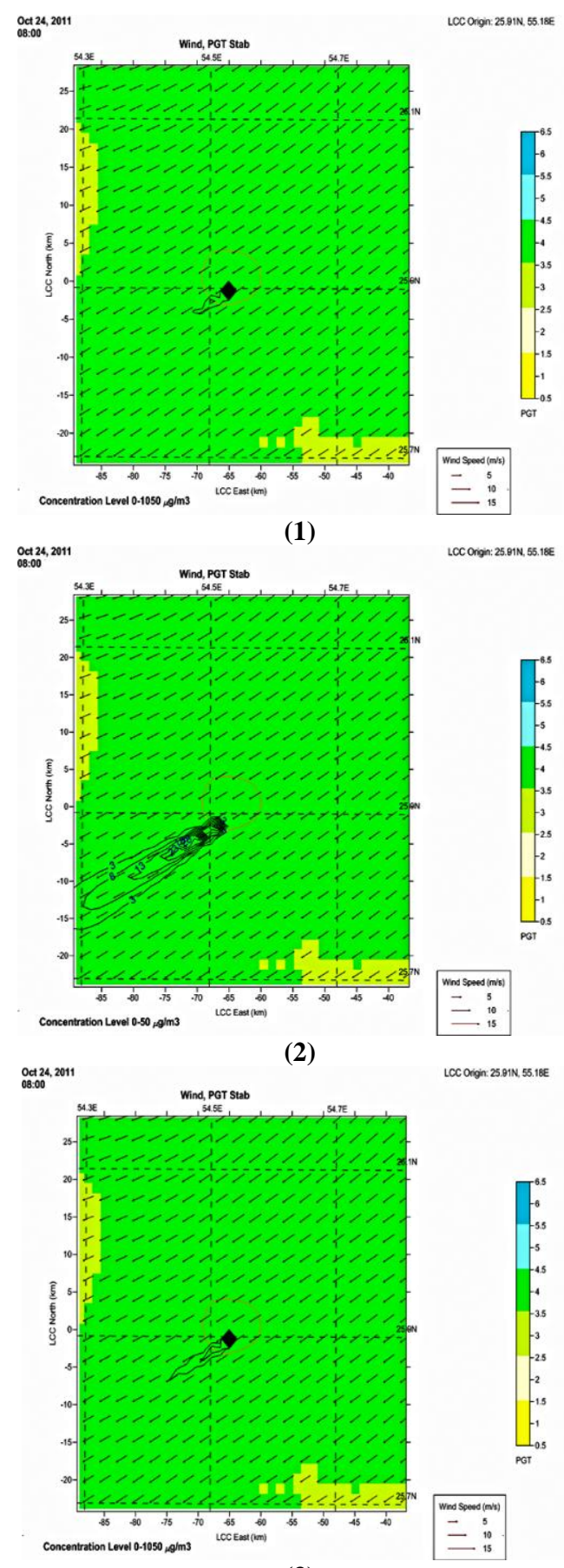

(3)

Figure 9. Contours of $\mathrm{SO}_{2}$ concentration distribution for (1) only short flares, (2) only elevated flares, (3) both elevated and short flares, 24 October 2011, 8:00 
and mixing height, so it reached the ground reached the ground level in a shorter distance, and because of low dispersion in horizontal and vertical directions that means lower dilution of pollutant with air, the concentration would be high.

The impact of stability and mixing height could be shown better when comparing the maximum and minimum conditions. For better representation of the effect of atmospheric stability and mixing height on the dispersion of air pollutant from flares, the contours of $\mathrm{SO}_{2}$ concentrations distribution for two cases were shown in Figure 10.
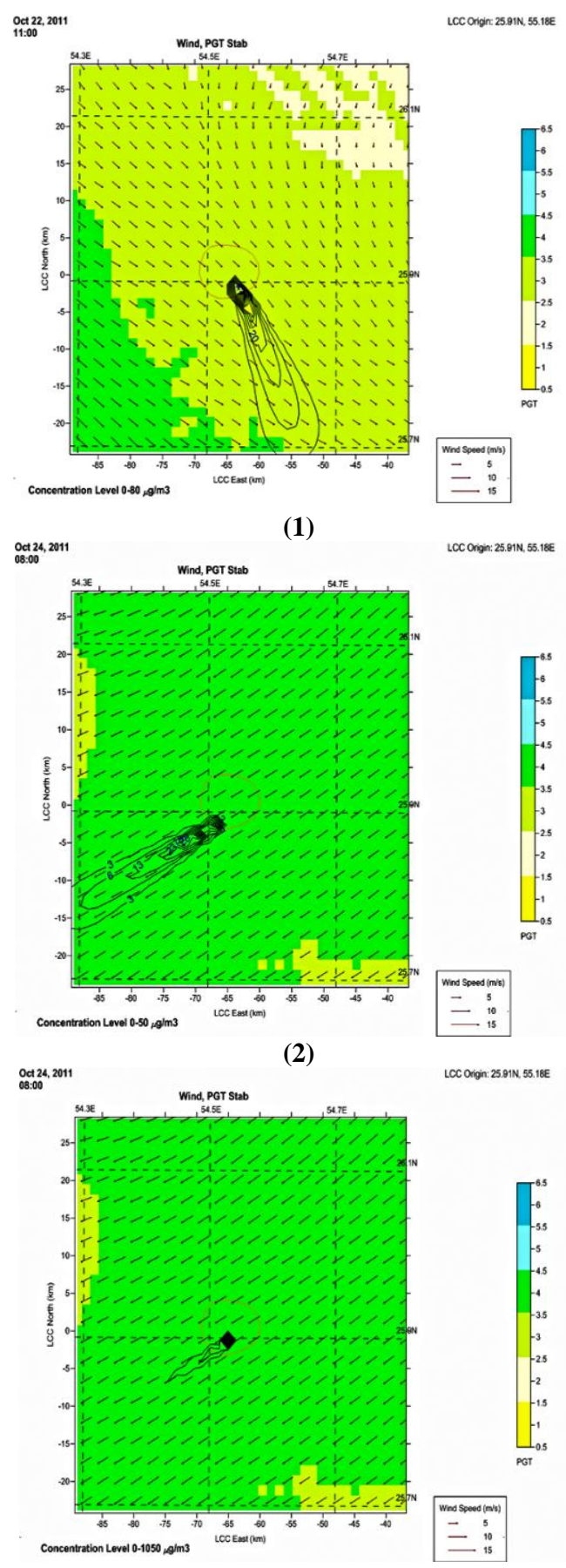

(3)

Figure 10. Contours of $\mathrm{SO}_{2}$ concentration distribution for (1) only short flares, (2) only elevated flares, (3) both elevated and short flares, 22 October 2011, 11:00
As it is depicted in the above figures, by increasing the instability of the atmosphere and mixing height, emission from low-height flares was also dispersed in both horizontal and vertical directions, which causes lower ground level concentration around flaring.

By comparing the maximum ground level concentration of $\mathrm{SO}_{2}$, which occurs in relatively stable condition and the unstable condition, it can be understood that most of the ground level concentration of air pollutant from flares caused by flares with low height. The impact of elevated flares are at longer distances from flaring activity, and in this study, their effect is mostly out of the island.

\section{CONCLUSION}

In this study, dispersion of an air pollutant, sulfur dioxide from gas flares on an island in Iran, which is one of the primary oil fields in the Persian Gulf, was investigated by application of CALPUFF model for two months of the year 2011. The effect of the terrain of modeling domain was considered in modeling. Since there was no option in this model for flares, modified flare parameters including emission rate and effective diameter and height of flare were calculated based on EPA guideline to represent better the actual flaring condition. The CALPUFF dispersion model, which is an unsteady state Lagrangian Gaussian model, was applied to investigate the effect of complex meteorological and terrain parameters that exist in locations like islands. The modeling was carried out with meteorological and geophysical data were provided by WRF prognostic meteorological model. The result of the study showed that the maximum concentrations mostly occur near flaring zone and cover a part of the industrial area. The objective of this study was the application of CALPUFF modeling system to investigate the effect of stability and mixing height on results of modeling. The result of modeling showed an excellent coupling of WRF model and CALPUFF modeling system. CALPUFF model could adequately express the effect of meteorological condition on results of modeling in each hour of the simulation period. The results of the simulation showed that low-height flares have the most impact on the ground level concentration of air pollutant on the islands. The effects of elevated flares were at a far distance from flaring activity and mostly occurred outside of the island.

\section{REFERENCES}

1. Soltanieh, M., Zohrabian, A., Gholipour, M.J. and Kalnay, E., 2016. A review of global gas flaring and venting and impact on the environment: Case study of Iran. International Journal of Greenhouse Gas Control, 49, pp.488-509.

2. Umukoro, G.E. and Ismail, O.S., 2017. Modelling emissions from natural gas flaring. Journal of King Saud University-Engineering Sciences, 29(2), pp.178-182.

3. Martin, J., Lumbreras, J. and Rodríguez, M.E., 2003. Testing flare emission factors for flaring in refineries. In 12th Annual Emission Inventory Conference, San Diego, USA, pp.1-7.

4. Tuaycharoen, P., Wongwises, P., Aram, R.P. and Satayopas, B., 2008 Nitrogen Oxide (NOx) dispersion model for Khanom power plant area. In International conference on environmental research and technology (ICERT 2008), Penang, Malaysia, pp.653-657. 
5. De Melo, A.M.V., Santos, J.M., Mavroidis, I. and Junior, N.C.R., 2012. Modelling of odour dispersion around a pig farm building complex using AERMOD and CALPUFF. Comparison with wind tunnel results. Building and Environment, 56, pp.8-20.

6. Abdul-Wahab, S.A., Al-Hajri, A. and Yetilmezsoy, K., 2016. Impact of the ambient air quality due to the dispersion of non-methane organic compounds from Barka Landfill. International journal of environmental science and technology, 13(4), pp.1099-1108.

7. Holnicki, P., Kałuszko, A. and Trapp, W., 2016. An urban scale application and validation of the CALPUFF model. Atmospheric Pollution Research, 7(3), pp.393-402.

8. Indumati, S., Oza, R.B., Mayya, Y.S., Puranik, V.D. and Kushwaha, H.S., 2009. Dispersion of pollutants over land-water-land interface: Study using CALPUFF model. Atmospheric Environment,43(2), pp.473-478.

9. Nagendra, S.S., Diya, M., Chithra, V.S., Menon, J.S. and Peter, A.E., 2016. Characteristics of air pollutants at near and far field regions of a national highway located at an industrial complex. Transportation Research Part D: Transport and Environment, 48, pp.1-13.

10. Yang, D., Wang, Z. and Zhang, R., Estimating Air Quality Impacts of Elevated Point Source Emissions in Chongqing, China. Aerosol and Air Quality Research, 8(3), pp.279-294.

11. Kesarkar, A.P., Dalvi, M., Kaginalkar, A. and Ojha, A., 2007. Coupling of the Weather Research and Forecasting Model with AERMOD for pollutant dispersion modeling. A case study for PM10 dispersion over Pune, India. Atmospheric Environment, 41(9), pp.1976-1988.

12. Abdul-Wahab, S.A., Ali, S., Sardar, S., Irfan, N. and Al-Damkhi, A., 2011. Evaluating the performance of an integrated CALPUFF-MM5 modeling system for predicting $\mathrm{SO}_{2}$ emission from a refinery. Clean Technologies and Environmental Policy, 13(6), pp.841-854.
13. Ghannam, K. and El-Fadel, M., 2013. Emissions characterization and regulatory compliance at an industrial complex: an integrated MM5/CALPUFF approach. Atmospheric Environment, 69, pp.156169.

14. Wu, H., Zhang, Y., Yu, Q. and Ma, W., 2018. Application of an integrated Weather Research and Forecasting (WRF)/CALPUFF modeling tool for source apportionment of atmospheric pollutants for air quality management: A case study in the urban area of Benxi, China. Journal of the Air \& Waste Management Association, 68(4), pp.347-368.

15. Pazoki, M. and Hasanidarabadi, B., 2017. Management of toxic and hazardous contents of oil sludge in Siri Island. Global Journal of Environmental Science and Management, 3(1), pp.33-42.

16. Iranian offshore oil company (IOOC) 2018. Available: http://www.iooc.co.ir/ENDefault.aspx [Accessed].

17. Scire, J.S., Strimaitis, D.G. and Yamartino, R.J., 2000. A User's Guide for the CALPUFF Dispersion Model (Version 5), Earth Tech.

18 Ep-d, E. C. N., Brashers, B. and Emery, C. 2013. The Mesoscale Model Interface Program (MMIF) Version 3.0, 2013-09-30.

19. Azadi, M., Shirgholami, M.R., Hajjam, S. and Sahraian, F., 2012. WRF Model Output Postprocessing for Daily Precipitation over Iran. IranWater Resources Research, 7(4), pp.71-81.

20. Cimorelli, A.J., Perry, S.G., Venkatram, A., Weil, J.C., Paine, R.J., Wilson, R.B., Lee, R.F., Peters, W.D. and Brode, R.W., 2005. AERMOD: A dispersion model for industrial source applications. Part I: General model formulation and boundary layer characterization. Journal of applied meteorology, 44(5), pp.682-693.

21. Brode, R. W., 1995. SCREEN 3 Model User's Guide. NASA 19980015351.

22. Leahey, D.M. and Davies, M.J.E., 1984. Observations of plume rise from sour gas flares. Atmospheric Environment, 18(5), pp.917-922.

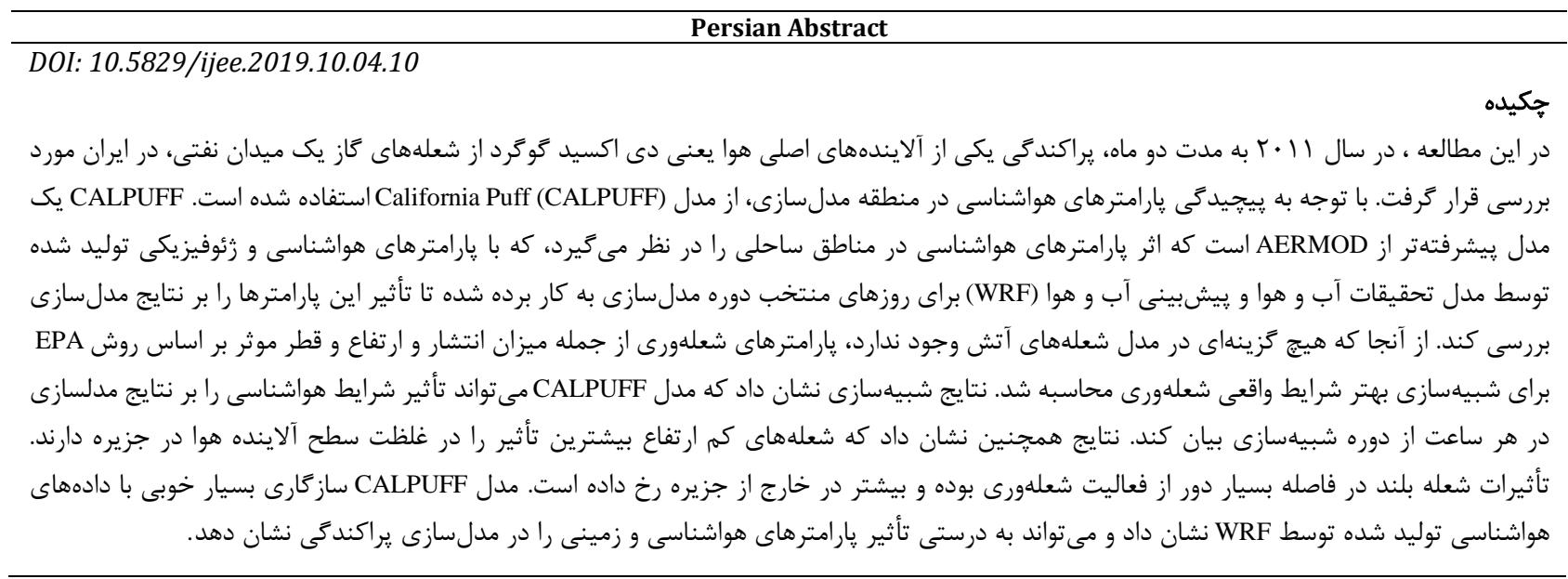

